\title{
De lo formal a lo real. Análisis de la participación familiar en asociaciones de madres y padres y consejos escolares
}

\author{
Mª Ángeles Gomariz Vicente, Joaquín Parra Martínez, Mª Paz García Sanz y Mª Ángeles Hernández Prados
}

Universidad de Murcia

\section{RESUMEN}

La legislación vigente contempla el derecho de las familias a participar en los centros educativos desde las Asociaciones de Madres y Padres del Alumnado (AMPA) y el Consejo Escolar (CE). Con la finalidad de conocer la participación de los progenitores de los discentes de Educación Infantil, Primaria y Secundaria en dichos órganos de representación familiar, mediante una investigación cuantitativa no experimental, con carácter evaluativo, se han utilizado 30 ítems dicotómicos de un cuestionario más amplio aplicado a 14876 familias pertenecientes a 16 comunidades autónomas españolas. Tras los análisis descriptivos e inferenciales de los datos, los resultados arrojan niveles de participación asociados a la AMPA en la mitad de las familias, escaso interés por formar parte de su Junta Directiva y una reducida presencia en las actividades organizadas por la asociación, señalando la imposibilidad de conciliación como principal obstáculo. La participación en el CE es muy baja, alegando la escasa competencia para desarrollar la representación en este órgano. En función de las variables analizadas, la participación formal de las familias es significativamente mayor en la etapa de Educación Primaria y en los centros públicos. No obstante, el tamaño del efecto no alcanzó los valores mínimos requeridos. La conclusión global del estudio es que la participación efectiva de las familias en los centros educativos es mejorable en intensidad y en diversidad.

Palabras Clave: Participación, familias, Asociaciones de Madres y Padres del Alumnado (AMPA), consejo escolar (CE), Dificultades.

\section{Analysis of the family participation in associations of parents of students and school council}

\section{ABSTRACT}

The legislation takes into account the right of families to participate in Parent's Associations and the School Council. In order to learn about the participation of parents in such associations of family representation, through a non-experimental quantitative research, for the purpose of assessment, 30 dichotomous items have been used in an open-ended questionnaire applied to 14876 families from 16 Spanish autonomous communities. After the descriptive and inferential analysis of the data, the results show some level of participation associated with the AMPA in half of the sample of families, little interest in being part of the board of directors and limited participation in the activities organized by the association, pointing out the impossibility of work-life balance as the main obstacle. Participation in the CE is considered very low, claiming their limited competence to develop the representation in this organ. According to the variables analyzed, the formal family participation is significantly higher in the stage of Primary Education and in public schools. However, the effect size did not reach the minimum values required. The final conclusion of the research is that effective family participation in the schools could be improved both in intensity and diversity.

Keywords: Participation, Families, Parents' association, School Council, Difficulties.

\section{Introducción}

La participación de las familias en los centros escolares es una cuestión de derecho que ha sido plasmada reiteradamente en la legislación educativa desde la Ley Moyano de 1857 hasta la actualidad (Feito, 2014; Frías, 2014), así como en el Artículo 27 de la Constitución Española (1978), en el que se determina que el profesorado, el alumnado y las familias intervendrán en el con- trol y gestión de los centros públicos, en los términos que la ley establezca (art. 27.7), así como el derecho de asociación (art. 22). Estas políticas participativas proporcionan un marco legal regulador que no garantiza la homogeneización de las familias ni de los centros educativos_(Garreta, 2012). Además, "no siempre se ha considerado necesaria y, cuando así ha sido, su aplicación práctica ha comportado resistencias por parte de las dos instituciones: familia y escuela" (Garreta, 2010, p. 47). 
La ley determina que las familias pueden y deben tener presencia en la vida de los centros a través de las Asociaciones de Madres y Padres del Alumnado (AMPA) y el Consejo Escolar (CE), de modo que mimetiza las formas de la representación parlamentaria en la vida de la escuela. A pesar de su capacidad predictiva, las leyes educativas, son insuficientes para el desarrollo de una cultura participativa (Rodrigo, Martínez-González y Rodríguez-Ruiz, 2018), tal y como se evidencia en los escasos niveles de participación familiar, a pesar de que son valorados positivamente por la comunidad educativa (Gomariz et al., 2008), siendo mayor en las vías de participación individual que en las colectivas (Parra, García Sanz, Gomariz y Hernández Prados, 2014) y casi anecdótica en las AMPA y CE (Feito, 2014), especialmente en contextos multiculturales. Según García-Sanz, Hernández-Prados, Parra y Gomariz (2016) existen diferentes perfiles de participación familiar, pero en todos ellos se recoge una menor participación de las familias en los CE y las AMPA.

Los CE y las AMPA constituyen vías de participación colectiva capaces de contribuir a la gestión del centro escolar en función de la voluntad, intenciones y formación del profesorado para trabajar colaborativamente con las familias (Hernández-Prados y López-Lorca, 2006). Desde estos espacios privilegiados de participación se puede incidir en el desarrollo de diversas actividades y acciones para la mejora de la calidad educativa y potenciación integral del alumnado.

Las AMPA han ido evolucionando en sus funciones, y a pesar de que éstas se concretan de forma específica en cada centro en función del proyecto educativo, se puede afirmar que han pasado de tener un papel más reivindicativo a la prestación de servicios (Garreta, 2016). Entre sus funciones destacan (Garreta, 2012): participar en el Consejo Escolar (94,4\%); organizar actividades extraescolares para alumnado $(87,9 \%)$; organizar actividades para los propios padres $(66,5 \%)$; colaborar con la federación de AMPA (64,8\%); participar en el programa general del centro $(60,1 \%)$ y organizar escuelas de padres $(44,8 \%)$. Su funcionamiento se caracteriza normalmente por un alto número de asociados y una escasa participación, así como la organización de actividades y espacios del centro, la comunicación, las actitudes y dinámicas de trabajo docente y las actitudes y expectativas de las familias (Llevot y Bernad, 2015).

Según Luengo y Molina (2016) la "Nueva Gestión Pública" enfatiza el sentimiento de impotencia derivado de la falta de autonomía en la toma de decisiones y limita el papel de las AMPA en la identificación y eliminación de las barreras de aprendizaje (modelo inclusivo) y en el fomento de la participación de todos los colectivos (democratización de las escuelas). Para la mayoría de estas asociaciones uno de los principales problemas lo constituye la escasa participación de las familias en las actividades que organizan. Si bien, siguiendo los datos de Garreta (2008) la media de inscripción al AMPA se sitúa en el 57,5\% y la de asistencia a las reuniones es del 18,3\%, más esperanzadores se muestran los resultados obtenidos por Martínez-González, Rodríguez-Ruiz y Gimeno (2010) en lo que respecta a inscripción (76\%), organización (78\%) y asistencia a las actividades (49\%). Asimismo, las familias inmigrantes tienen una actividad muy débil o inexistente en las AMPA (Garreta, 2008), lo que, en parte, depende de los esfuerzos y actividades que organiza cada AMPA para llegar a ellas.

Si a la complejidad y diversidad de la participación (Epstein, 2011; Llevot y Bernad, 2015), se une la imagen de las AMPA como prestadoras de servicios y de las familias como meras consumidoras (Paniagua, 2013), desprovistas de un rol activo en la dinámica educativa (Calvo, Verdugo y Amor, 2016), y de los centros educativos, no como referentes de vida comunitaria, sino como instituciones herméticas (Pañellas y Alguacil, 2009), el panorama aún es más desolador. Según Bernad y Llevot (2016) las dificultades de participación en la AMPA se clasifican en cuatro categorías: socioculturales (falta de tradición participativa y cultura asociativa), socioeconómicas (conciliación, cuotas), institucionales (desconocimiento, poca representatividad, escaso liderazgo o actitudes docentes) y personales (escaso compromiso, individualismo, infravaloración, etc.).

En lo que respecta al CE, a pesar de ser definido como el principal órgano de participación de la comunidad educativa, cuya finalidad consiste en favorecer el debate, la reflexión y la mejora de la educación en los centros educativos (Mesa, 2014), ni profesores ni padres lo perciben como un medio real facilitador de la participación (Llevot y Bernad, 2015). De hecho, tal y como señala Feito (2014), las competencias del Consejo Escolar se han visto reducidas en la LOECE (1980), LOCE (2002) y LOMCE (2013), y potenciadas en la LODE (1985) y LOE (2006), quedando finalmente el CE limitado a un órgano meramente consultivo, suprimiendo las competencias de control y gestión, lo que no beneficia, según Mesa (2014), ni a la democracia ni a la educación.

Las competencias del CE en relación con las familias consisten en "Conocer la resolución de conflictos disciplinarios y velar por que se atengan a la normativa vigente. Cuando las medidas disciplinarias adoptadas por el director correspondan a conductas del alumnado que perjudiquen gravemente la convivencia del centro, el Consejo Escolar, a instancia de padres, madres o tutores legales, podrá revisar la decisión adoptada y proponer, en su caso, las medidas oportunas" (LOE artículo 127.f.). Sin embargo, el último informe del Consejo Escolar del Estado recomienda que el CE debe promover la toma de decisiones verdaderamente participativas, que tengan competencia para aprobar el proyecto de centro y que se proporcione formación a sus miembros, ya que a menudo no tienen la formación suficiente para ejercer su función de forma óptima, y esto dificulta la eficacia y el buen funcionamiento de dichos órganos, limitándose a ratificar las decisiones del equipo directivo, sin que se les permita analizar en profundidad los documentos que aprueban y reflexionar sobre las decisiones que toman (Consejo Escolar del Estado, 2017). En otras palabras, "El Consejo Escolar, dominado por el profesorado, suele ser la caja de resonancia de la política del director" (Martín Bris y Garín, 2007, p.17).

Según el estudio de Garreta (2008) la actividad del Consejo Escolar queda relegada a un papel meramente secundario, encabezando la cola de las modalidades de participación a las que otorgan mayor interés, pues tan solo un 2,7\% de las familias selecciona a este órgano como el motor de la participación. Por otro lado, el estudio de Santos (1997) puso de manifiesto que la participación de las familias en el CE resulta inoperante porque existen elementos inhibidores procedentes de las familias y del profesorado asociados a la carencia de recursos verbales, sentido del ridículo, desinformación técnica y legislativa, complejo de inferioridad sociocultural, conciencia del poder sancionador del profesorado sobre sus hijos y falta de tiempo. Las cifras de participación en las elecciones a CE en los centros españoles se sitúa en porcentajes medios que oscilan entre el 16\% de media en los centros de Infantil y Primaria y el escaso $4 \%$ que ofrecen los centros de Secundaria, siendo ligeramente superior en los centros públicos frente a los privados concertados (Parra et al., 2014).

Los intentos de regulación de las AMPA y los CE han contribuido a la formalización y burocratización de los mismos, pero no han incrementado los niveles de participación y colaboración, más bien lo contrario. Asistimos a una participación deseada pero no lograda, formal pero no real, normativa pero no formativa (Parra et al., 2014; Torres, 2013), siendo necesario promover un 
cambio no solo organizativo y estructural, sino también cultural (Rivas y Ugarte, 2014) que comience con la puesta en práctica de actuaciones que respondan a las necesidades de las familias (Llevot y Bernad, 2015). De ahí la necesidad imperiosa de plantear como finalidad de este estudio: 1) analizar la participación de las familias en las AMPA y CE de los centros en los que cursan estudios sus hijos e hijas, a nivel global, así como 2) observar dicha participación en función de la etapa educativa y de la titularidad del centro.

\section{Método}

La investigación se integra dentro de los métodos cuantitativos no experimentales. Se trata de un estudio descriptivo exploratorio tipo encuesta, con carácter evaluativo.

\subsection{Participantes}

En el estudio han participado 14876 familias, cuyos hijos e hijas cursan estudios en centros escolares españoles en Educación Infantil, Primaria y Secundaria. El muestreo fue aleatorio estratificado en todo el territorio nacional (excepto Cataluña por autoexclusión), atendiendo a las variables: comunidad autónoma, etapa educativa y titularidad del centro.

Participaron familias de 16 comunidades autónomas más la ciudad de Melilla, distribuidas de la siguiente forma: Andalucía $(20,1 \%)$, Aragón (4,4\%), Asturias (3,4\%), Baleares (4,7\%), Cana- rias $(3,9 \%)$, Cantabria $(1,2 \%)$, Castilla La-Mancha $(6,7 \%)$, Castilla y León $(6,1 \%)$, Comunidad Valenciana (13,3\%), Extremadura $(3,7 \%)$, Galicia $(7,6 \%)$, La Rioja $(0,6 \%)$, Madrid (17,4\%), Melilla $(0,3 \%)$, Navarra $(1,0 \%)$, País Vasco $(3,0 \%)$ y Región de Murcia $(2,6 \%)$. El 17\% de las familias participantes tenía a sus hijos escolarizados en Educación Infantil, el 47,3\% en Educación Primaria y el 34,9\% en Educación Secundaria Obligatoria. El 68,3\% de los centros son de titularidad pública, el 26,2\% lo constituyen centros concertados y el 5,4\% lo conforman centros privados.

En función de quien contestaba el cuestionario, las madres han sido las participantes mayoritarias $(60,7 \%)$, seguidas de ambos progenitores $(26,6 \%)$ y de los padres $(9,9 \%)$.

\subsection{Variables e instrumento de recogida de información}

Las variables de agrupación consideradas en el estudio fueron: etapa educativa y titularidad del centro, mientras que las variables criterio han sido: participación de las familias en la AMPA y participación de las familias en el CE.

La recogida de información se llevó a cabo con un amplio cuestionario de 141 ítems, aplicado en formato papel y coordinado por el Consejo Escolar del Estado. Para esta investigación, además de los dos ítems referidos a las variables de agrupación mencionadas, se han empleado 30 ítems de naturaleza dicotómica (SI/NO), los cuales, en el cuestionario más amplio constituyen la dimensión "Participación familiar en la AMPA y en el CE" (Tabla 1).

Tabla 1.

Ítems del cuestionario utilizados en la investigación: dimensión "Participación familiar en la AMPA y en el CE"

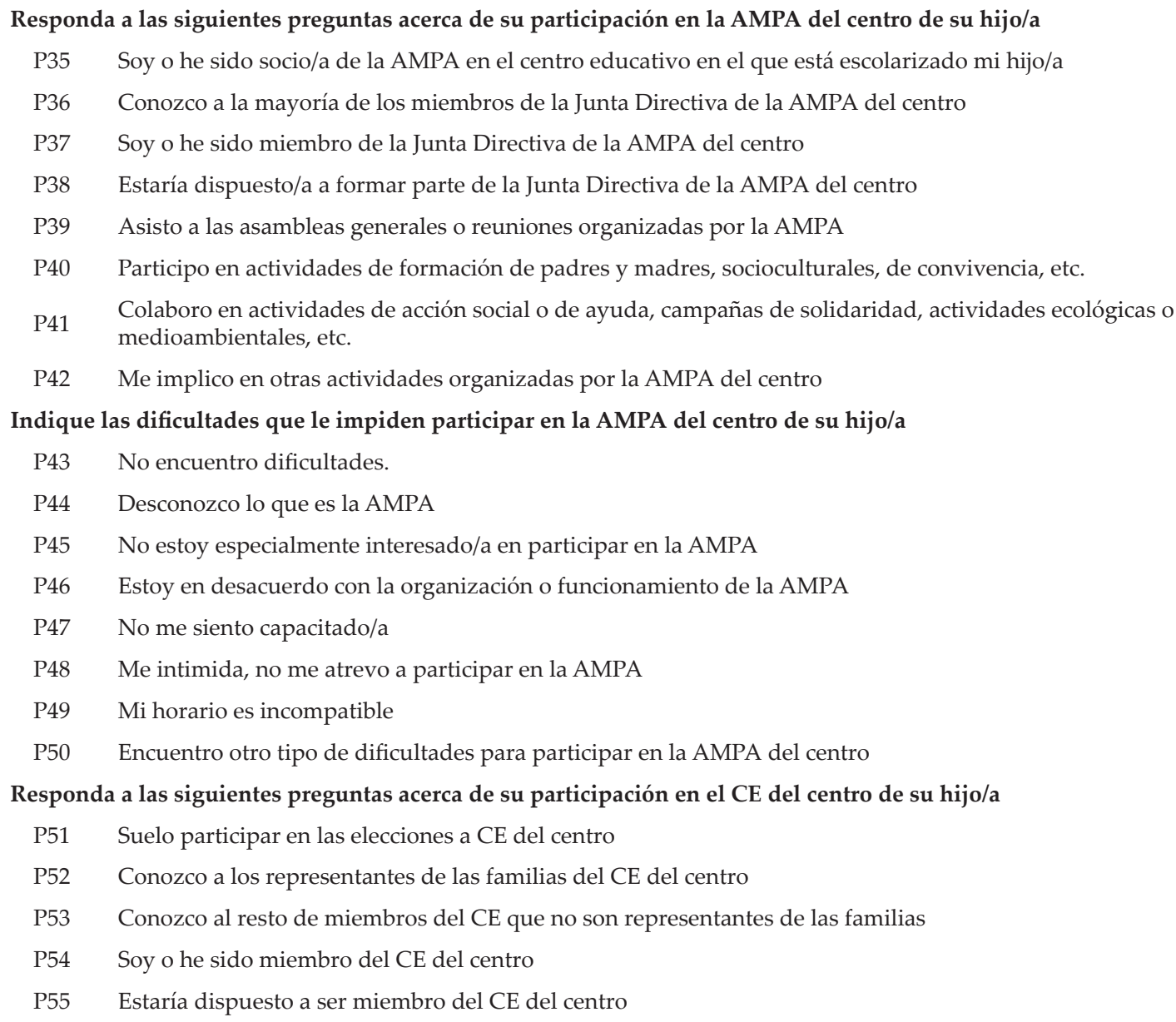




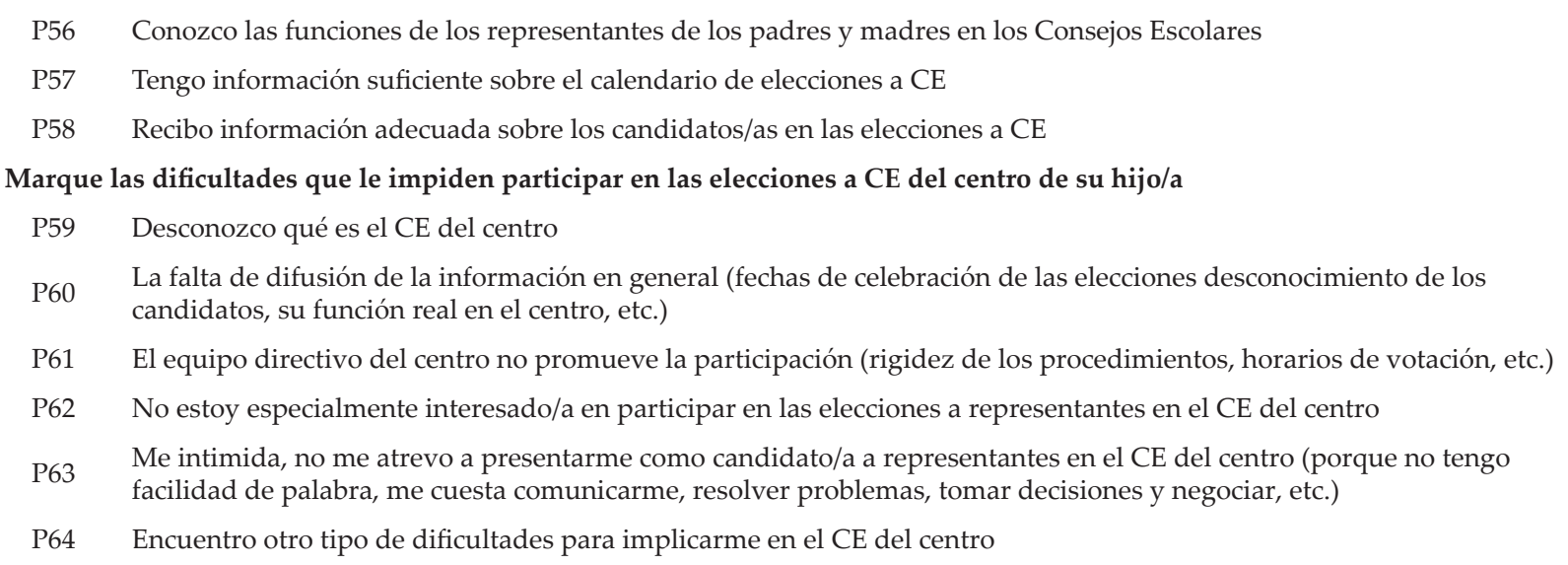

La validez de contenido del cuestionario se obtuvo mediante el juicio de expertos de siete profesores de diferentes universidades españolas. Asimismo, la fiabilidad del instrumento completo resultó ser altamente satisfactoria (De Vellis, 2003), ya que se alcanzó un coeficiente alpha de Cronbach de 0,867, si bien la fiabilidad de los 30 ítems considerados en esta investigación (dimensión "Participación familiar en la AMPA y en el CE") fue de 0,683.

\subsection{Técnicas de análisis de datos}

Para obtener los resultados de la investigación, se utilizó el paquete estadístico SPSS v.19, recurriéndose tanto a la estadística descriptiva (frecuencias y porcentajes) como a la inferencial no paramétrica (prueba Chi Cuadrado). El nivel de significación estadística fue de $\alpha=0,05$.

Teniendo en cuenta que las diferencias significativas lo que demuestran es que es poco probable que dichas diferencias sean debidas al azar, pero no la magnitud o fuerza de las mismas, en los casos en los que hubo significación estadística, se calculó el coeficiente de contingencia para determinar la magnitud de la asociación (tamaño del efecto) entre las categorías de las variables consideradas (Cohen, 1988).

\section{Resultados}

Los resultados de la investigación se muestran considerando los objetivos formulados en la misma.

\subsection{Participación global de las familias en la AMPA y en el CE}

Respecto a la participación global de las familias en la AMPA del centro, más de la mitad son o han sido socios/as de dicha asociación (57,3\%); sin embargo, un porcentaje parecido no conoce a los progenitores de su Junta Directiva (55,6\%); la gran mayoría no ha formado nunca parte de dicha Junta $(86,1 \%)$ y dos tercios de las familias no se prestan a ser miembros de la misma (69\%). Aproximadamente este mismo porcentaje no participa en las asambleas generales o reuniones de la AMPA (64,5\%); casi las tres cuartas partes tampoco lo hace en actividades de formación familiar (72\%); bastante más de la mitad no se implica en actividades de acción social (61,4\%); y apenas el 20\% participa en otras actividades organizadas por la AMPA (Tabla 2).

Por otro lado, las tres cuartas partes de las familias participantes encuentra algún tipo de dificultad para implicarse en la AMPA $(74,5 \%)$, ya sea por desconocimiento de la asociación (3\%), por estar en desacuerdo con su organización o funcionamiento $(4,9 \%)$, por no sentirse capacitadas (4\%) y/o porque les intimida la participación en la misma (2,7\%). Igualmente, el 40,9\% reconoce que su horario es incompatible y el 20,9\% de las familias no muestra interés especial en participar en dicha asociación (Tabla 2).

Tabla 2.

Frecuencias y porcentajes de la participación familiar en la AMPA del centro. Global

\begin{tabular}{ccccc} 
& \multicolumn{2}{c}{ Frecuencia } & \multicolumn{2}{c}{ Porcentaje } \\
Ítem & Sí & No & Sí & No \\
\hline P35 & 8527 & 5733 & $57,3 \%$ & $38,5 \%$ \\
P36 & 5908 & 8275 & $39,7 \%$ & $55,6 \%$ \\
P37 & 1249 & 12813 & $8,4 \%$ & $86,1 \%$ \\
P38 & 3645 & 10269 & $24,5 \%$ & $69 \%$ \\
P39 & 4325 & 9599 & $29,1 \%$ & $64,5 \%$ \\
P40 & 3057 & 10707 & $20,5 \%$ & $72 \%$ \\
P41 & 4571 & 9137 & $30,7 \%$ & $61,4 \%$ \\
P42 & 2940 & 8035 & $19,8 \%$ & $54 \%$ \\
P43 & 3796 & 11080 & $25,5 \%$ & $74,5 \%$ \\
P44 & 443 & 14433 & $3 \%$ & $97 \%$ \\
P45 & 3107 & 11769 & $20,9 \%$ & $79,1 \%$ \\
P46 & 732 & 14144 & $4,9 \%$ & $95,1 \%$ \\
P47 & 599 & 14277 & $4 \%$ & $96 \%$ \\
P48 & 395 & 14481 & $2,7 \%$ & $97,3 \%$ \\
P49 & 6008 & 8868 & $40,4 \%$ & $59,6 \%$ \\
P50 & 2636 & 12240 & $17,7 \%$ & $82,3 \%$ \\
\hline
\end{tabular}

En cuanto a la participación familiar global en el CE del centro, en la Tabla 3 se observa que un tercio de los progenitores participa en las elecciones a dicho órgano colegiado (32,5\%) y conoce a sus representantes $(32,4 \%)$ y en menor medida están al tanto del resto de personas que componen el CE $(22,6 \%)$. Únicamente el $5,4 \%$ de las familias es o ha sido miembro del CE, aunque el $23 \%$ estaría dispuesto a serlo. Por último, en torno a la mitad de los padres y madres encuestados conoce las funciones de los representantes de las familias en los respectivos CE $(44,3 \%)$, tiene información suficiente sobre las elecciones a CE $(51,2 \%)$ y sobre los candidatos y candidatas (46,5\%).

Con relación a las dificultades de las familias para participar en las elecciones a CE del centro, el 11,7\% desconoce lo que es este órgano colegiado, el 19,3\% opina que falta información sobre el proceso electoral y el 5,6\% percibe que el equipo directivo no promueve la participación. Del mismo modo, casi un tercio de las familias no está interesado en participar en las elecciones a CE (31,8\%). 
Tabla 3.

Frecuencias y porcentajes de la participación familiar en el CE del centro. Global

\begin{tabular}{ccccc} 
Ítem & \multicolumn{2}{c}{ Frecuencia } & \multicolumn{2}{c}{ Porcentaje } \\
& Sí & No & Sí & No \\
\hline P51 & 4840 & 9257 & $32,5 \%$ & $62,2 \%$ \\
P52 & 4816 & 9262 & $32,4 \%$ & $62,3 \%$ \\
P53 & 3356 & 10577 & $22,6 \%$ & $71,1 \%$ \\
P54 & 799 & 13244 & $5,4 \%$ & $89 \%$ \\
P55 & 3424 & 10472 & $23 \%$ & $70,4 \%$ \\
P56 & 6594 & 7364 & $44,3 \%$ & $49,5 \%$ \\
P57 & 7613 & 6310 & $51,2 \%$ & $42,4 \%$ \\
P58 & 6910 & 6591 & $46,5 \%$ & $44,3 \%$ \\
P59 & 1740 & 13136 & $11,7 \%$ & $88,3 \%$ \\
P60 & 2870 & 12006 & $19,3 \%$ & $80,7 \%$ \\
P61 & 839 & 14037 & $5,6 \%$ & $94,4 \%$ \\
P62 & 4737 & 10139 & $31,8 \%$ & $68,2 \%$ \\
P63 & 13644 & 1232 & $91,7 \%$ & $8,3 \%$ \\
P64 & 4662 & 10214 & $31,3 \%$ & $68,7 \%$ \\
\hline
\end{tabular}

\subsection{Participación familiar considerando la etapa educativa y la titularidad del centro}

Implicación de las familias en la AMPA y CE, en función de la etapa educativa

Respecto a los ítems relacionados con la participación familiar en la AMPA del centro, en función la etapa cursada por el alumnado, según los datos de la Tabla 4, los padres y madres del alumnado de Educación Primaria se implican más en la AMPA (con un porcentaje medio de 33,46\%), seguidos de los de Infantil $(28,49 \%)$ y de los de Secundaria $(22,40 \%)$, siendo estos últimos los que encuentran más dificultades para participar en dicha asociación $(14,39 \%)$.

Tabla 4.

Frecuencias y porcentajes de la participación familiar en la AMPA del centro, en función de la etapa educativa

\begin{tabular}{|c|c|c|c|c|c|c|c|c|c|c|c|c|}
\hline \multirow{3}{*}{ Ítem } & \multicolumn{6}{|c|}{ Frecuencia } & \multicolumn{6}{|c|}{ Porcentaje (\%) } \\
\hline & \multicolumn{2}{|c|}{ Infantil } & \multicolumn{2}{|c|}{ Primaria } & \multicolumn{2}{|c|}{ Secundaria } & \multicolumn{2}{|c|}{ Infantil } & \multicolumn{2}{|c|}{ Primaria } & \multicolumn{2}{|c|}{ Secundaria } \\
\hline & Sí & No & Sí & No & Sí & No & Sí & No & Sí & No & Sí & No \\
\hline P35 & 1272 & 1062 & 4445 & 2238 & 2575 & 2220 & 51,9 & 43,3 & 64,3 & 32,4 & 51,3 & 44,2 \\
\hline P36 & 915 & 1397 & 3413 & 3236 & 1416 & 3362 & 37,3 & 57 & 49,4 & 46,8 & 28,2 & 66,9 \\
\hline P37 & 141 & 2148 & 743 & 5837 & 334 & 4421 & 5,8 & 87,6 & 10,7 & 84,4 & 6,7 & 88,0 \\
\hline P38 & 761 & 1527 & 1824 & 4682 & 935 & 3746 & 31 & 62,3 & 26,4 & 67,7 & 18,6 & 74,6 \\
\hline P39 & 695 & 1577 & 2278 & 4270 & 1224 & 3450 & 28,3 & 64,3 & 32,9 & 61,8 & 24,4 & 68,7 \\
\hline $\mathrm{P} 40$ & 503 & 1742 & 1693 & 4788 & 776 & 3846 & 20,5 & 71 & 24,5 & 69,3 & 15,5 & 76,6 \\
\hline P41 & 798 & 1431 & 2536 & 3903 & 1100 & 3525 & 32,5 & 58,4 & 36,7 & 56,5 & 21,9 & 70,2 \\
\hline $\mathrm{P} 42$ & 506 & 1257 & 1714 & 3404 & 634 & 3134 & 20,6 & 51,3 & 24,8 & 49,2 & 12,6 & 62,4 \\
\hline P43 & 668 & 1784 & 1956 & 4958 & 1066 & 3956 & 27,2 & 72,8 & 28,3 & 71,7 & 21,2 & 78,8 \\
\hline P44 & 85 & 2367 & 167 & 6747 & 177 & 4845 & 3,5 & 96,5 & 2,4 & 97,6 & 3,5 & 96,5 \\
\hline P45 & 457 & 1995 & 1309 & 5605 & 1246 & 3776 & 18,6 & 81,4 & 18,9 & 81,1 & 24,8 & 75,2 \\
\hline P46 & 90 & 2362 & 404 & 6510 & 217 & 4805 & 3,7 & 96,3 & 5,8 & 94,2 & 4,3 & 95,7 \\
\hline P47 & 67 & 2385 & 272 & 6642 & 243 & 4779 & 2,7 & 97,3 & 3,9 & 96,1 & 4,8 & 95,2 \\
\hline P48 & 71 & 2381 & 172 & 6742 & 141 & 4881 & 2,9 & 97,1 & 2,5 & 97,5 & 2,8 & 97,2 \\
\hline P49 & 941 & 1511 & 2804 & 4110 & 2081 & 2941 & 38,4 & 61,6 & 40,6 & 59,4 & 41,4 & 58,6 \\
\hline P50 & 387 & 2065 & 1201 & 5713 & 959 & 4063 & 15,8 & 84,2 & 17,4 & 82,6 & 19,1 & 80,9 \\
\hline
\end{tabular}

Como se muestra en la Tabla 5, la prueba Chi Cuadrado $\left(X^{2}\right)$ evidenció diferencias significativas entre Infantil y Primaria en todos los ítems relativos a la participación familiar en la AMPA del centro (del P35 al P42), y en las siguientes dificultades: desconocimiento de lo que es la AMPA (P44), desacuerdo con su funcionamiento (P46) y falta de capacitación (P47). De igual modo, entre Primaria y Secundaria se hallaron diferencias significativas en todos los ítems analizados, a excepción de: no atreverse a participar en la asociación por intimidación (P48) e incompatibilidad de horarios (P49).
Entre Infantil y Secundaria la significación estadística se encontró en el conocimiento de los miembros de la Junta directiva de la AMPA (P36), disposición para formar parte de dicha Junta (P38), participación en reuniones de la AMPA (P39), participación en actividades de formación de padres y madres, socioculturales y de convivencia (P40), implicación en actividades de diversa índole (P41), participación en otras actividades (P42), número de dificultades para participar en la asociación (P43), desinterés para la participación (P45), falta de capacitación (P47), incompatibilidad horaria (P49) y otras dificultades (P50). 
Tabla 5.

Significación estadística de la participación familiar en la AMPA del centro, en función de la etapa educativa

\begin{tabular}{|c|c|c|c|c|c|c|}
\hline & \multicolumn{2}{|c|}{$\begin{array}{l}\text { Infantil- } \\
\text { Primaria }\end{array}$} & \multicolumn{2}{|c|}{$\begin{array}{l}\text { Primaria- } \\
\text { Secundaria }\end{array}$} & \multicolumn{2}{|c|}{$\begin{array}{l}\text { Infantil- } \\
\text { Secundaria }\end{array}$} \\
\hline & $X^{2}$ & Sig. & $X^{2}$ & Sig. & $X^{2}$ & Sig. \\
\hline P35 & 107,592 & ,000 & 192,871 & ,000 & ,401 &, 526 \\
\hline P36 & 94,927 & ,000 & 536,281 & ,000 & 69,762 & ,000 \\
\hline P37 & 49,840 & ,000 & 58,464 & ,000 & 1,835 & , 175 \\
\hline P38 & 22,265 & ,000 & 95,214 & ,000 & 147,326 & ,000 \\
\hline P39 & 13,312 & ,000 & 93,997 & ,000 & 14,819 & ,000 \\
\hline P40 & 12,234 & ,000 & 135,908 & ,000 & 31,445 &, 000 \\
\hline P41 & 8,987 & ,003 & 296,936 & ,000 & 108,476 &, 000 \\
\hline P42 & 13,759 & ,000 & 309,970 & ,000 & 103,509 & ,000 \\
\hline P43 & ,985 & ,321 & 76,767 & ,000 & 33,471 &, 000 \\
\hline P44 & 7,639 & ,006 & 12,785 & ,000 & ,016 & ,898 \\
\hline P45 & 103 & 749 & 59,747 & ,000 & 35,684 &, 000 \\
\hline P46 & 17,103 & ,000 & 13,667 & ,000 & 1,770 & 183 \\
\hline P47 & 7,492 & ,006 & 5,767 & ,016 & 18,384 & ,000 \\
\hline P48 & 1,192 & 275 & 1,166 & 280 & ,046 & ,830 \\
\hline P49 & 3,580 & ,058 & ,937 & ,333 & 6,409 &, 011 \\
\hline P50 & 3,240 & ,072 & 5,843 & ,016 & 12,469 &, 000 \\
\hline
\end{tabular}

La Tabla 6 indica que, a pesar de que se hallaron diferencias significativas entre las tres etapas educativas, en la mayoría de los ítems estudiados, los respectivos coeficientes de contingencia pusieron de manifiesto que en ningún caso se alcanzó el denominado valor típico $(r=0,3)$ establecido por Cohen (1988).
Tabla 6.

Coeficientes de contingencia de los ítems con significación estadística relativos a la participación familiar en la AMPA del centro, en función de la etapa educativa

\begin{tabular}{|c|c|c|c|}
\hline & $\begin{array}{l}\text { Infantil- } \\
\text { Primaria }\end{array}$ & $\begin{array}{l}\text { Primaria- } \\
\text { Secundaria }\end{array}$ & $\begin{array}{l}\text { Infantil- } \\
\text { Secundaria }\end{array}$ \\
\hline & $\begin{array}{c}\text { Coeficiente } \\
\text { contingencia }\end{array}$ & $\begin{array}{c}\text { Coeficiente } \\
\text { contingencia }\end{array}$ & $\begin{array}{c}\text { Coeficiente } \\
\text { contingencia }\end{array}$ \\
\hline P35 & 109, & 129, & -- \\
\hline P36 & 102, & 212, & 099, \\
\hline P37 & 075, & 072, & -- \\
\hline P38 & ,050 & 092, & 144 \\
\hline P39 & 039 & 091 & ,046 \\
\hline P40 & 037 & 110, & ,068 \\
\hline P41 & 032 & 162, & 125, \\
\hline P42 & 045, & 184 & 136 \\
\hline P43 & -- & 080, & 067 \\
\hline P44 & ,029 & 033, & -- \\
\hline P45 & -- & 071 & 069, \\
\hline P46 & 043, & ,034 & -- \\
\hline P47 & 028 & ,022 & 050 \\
\hline P48 & -- & -- & -- \\
\hline P49 & -- & -- & 029 \\
\hline P50 & -- & ,022 & 040 \\
\hline
\end{tabular}

Con relación a la participación familiar en el CE del centro, la Tabla 7 indica que los mayores porcentajes se dan en Primaria (36,49\% de participación media), mientras que los índices más bajos son compartidos entre las familias de Infantil $(28,46 \%)$ y Secundaria (28,52\%). Respecto a las dificultades para participar en las elecciones a CE, se encuentran bastante repartidas en las tres etapas educativas, si bien se aprecian porcentajes mayores en Secundaria $(18,68 \%)$.

Tabla 7.

Frecuencias y porcentajes de la participación familiar en el CE del centro, en función de la etapa educativa

\begin{tabular}{|c|c|c|c|c|c|c|c|c|c|c|c|c|}
\hline \multirow{3}{*}{ Ítem } & \multicolumn{6}{|c|}{ Frecuencia } & \multicolumn{6}{|c|}{ Porcentaje (\%) } \\
\hline & \multicolumn{2}{|c|}{ Infantil } & \multicolumn{2}{|c|}{ Primaria } & \multicolumn{2}{|c|}{ Secundaria } & \multicolumn{2}{|c|}{ Infantil } & \multicolumn{2}{|c|}{ Primaria } & \multicolumn{2}{|c|}{ Secundaria } \\
\hline & Sí & No & Sí & No & Sí & No & Sí & No & Sí & No & Sí & No \\
\hline P51 & 652 & 1610 & 2650 & 3991 & 1404 & 3351 & 26,6 & 65,7 & 38,3 & 57,7 & 28 & 66,7 \\
\hline P52 & 660 & 1629 & 2770 & 3849 & 1253 & 3477 & 26,9 & 66,4 & 40,1 & 55,7 & 25 & 69,2 \\
\hline P53 & 457 & 1806 & 1958 & 4594 & 848 & 3833 & 18,6 & 73,7 & 28,3 & 66,4 & 16,9 & 76,3 \\
\hline P54 & 99 & 2178 & 476 & 6122 & 202 & 4530 & 4 & 88,8 & 6,9 & 88,5 & 4 & 90,2 \\
\hline P55 & 715 & 1546 & 1692 & 4845 & 904 & 3762 & 29,2 & 63,1 & 24,5 & 70,1 & 18 & 74,9 \\
\hline P56 & 920 & 1343 & 3312 & 3245 & 2175 & 2528 & 37,5 & 54,8 & 47,9 & 46,9 & 43,3 & 50,3 \\
\hline P57 & 1073 & 1160 & 3877 & 2673 & 2421 & 2281 & 43,8 & 47,3 & 56,1 & 38,7 & 48,2 & 45,4 \\
\hline P58 & 1007 & 1129 & 3441 & 2940 & 2250 & 2315 & 41,1 & 46 & 49,8 & 42,5 & 44,8 & 46,1 \\
\hline P59 & 386 & 2066 & 699 & 6215 & 595 & 4427 & 15,7 & 84,3 & 10,1 & 89,9 & 11,8 & 88,2 \\
\hline P60 & 515 & 1937 & 1301 & 5613 & 965 & 4057 & 21 & 79,0 & 18,8 & 81,2 & 19,2 & 80,8 \\
\hline P61 & 121 & 2331 & 423 & 6491 & 267 & 4755 & 4,9 & 95,1 & 6,1 & 93,9 & 5,3 & 94,7 \\
\hline P62 & 664 & 1788 & 2189 & 4725 & 1752 & 3270 & 27,1 & 72,9 & 31,7 & 68,3 & 34,9 & 65,1 \\
\hline P63 & 192 & 2260 & 597 & 6317 & 406 & 4616 & 7,8 & 92,2 & 8,6 & 91,4 & 8,1 & 91,9 \\
\hline P64 & 700 & 1752 & 2166 & 4748 & 1645 & 3377 & 28,5 & 71,5 & 31,3 & 68,7 & 32,8 & 67,2 \\
\hline
\end{tabular}


Tras calcular la prueba Chi Cuadrado, como se observa en la Tabla 8, se encontró significación estadística entre Infantil y Primaria en todos los aspectos investigados, excepto en lo que respecta a la inseguridad de las familias para presentarse como representante a las elecciones al CE (P63). Entre Primaria y Secundaria se apreció significación estadística en gran parte de los ítems analizados: participación en la elecciones a CE del centro (P51), conocimiento de los representantes de las familias (P52), conocimiento del resto de miembros del CE (P53), pertenecer a dicho órgano (P54), estar dispuesto/a a ser parte del mismo (P55), conocimiento de las funciones de los representantes de las familias en el CE (P56), información sobre el calendario de elecciones (P57), información sobre los candidatos/as (P58), desconocimiento de lo que es el CE (P59) y desinterés para participar en sus elecciones (P62). Por último, entre Infantil y Secundaria se observaron diferencias significativas en el conocimiento de los representantes (P52) y del resto de miembros del CE (P53), estar dispuesto a formar parte de dicho órgano (P55), conocimiento de las funciones de los representantes de las familias en el CE (P56), información sobre el calendario de elecciones del mismo (P57), desconocimiento del CE (P59), desinterés para participar en sus elecciones (P62) y otro tipo de dificultades (P64).

Tabla 8 .

Significación estadística de la participación familiar en el CE del centro, en función de la etapa educativa

\begin{tabular}{|c|c|c|c|c|c|c|}
\hline & \multicolumn{2}{|c|}{$\begin{array}{l}\text { Infantil- } \\
\text { Primaria }\end{array}$} & \multicolumn{2}{|c|}{$\begin{array}{l}\text { Primaria- } \\
\text { Secundaria }\end{array}$} & \multicolumn{2}{|c|}{$\begin{array}{l}\text { Infantil- } \\
\text { Secundaria }\end{array}$} \\
\hline & $X^{2}$ & Sig. & $X^{2}$ & Sig. & $X^{2}$ & Sig. \\
\hline P51 & 88,770 & ,000 & 130,187 & ,000 & ,365 & ,545 \\
\hline P52 & 121,685 & ,000 & 284,384 & ,000 & 4,271 & ,039 \\
\hline P53 & 79,395 & ,000 & 201,776 & ,000 & 4,319 & ,038 \\
\hline P54 & 22,956 & ,000 & 42,496 & ,000 & ,023 & ,879 \\
\hline P55 & 27,849 & ,000 & 64,798 & ,000 & 127,589 & ,000 \\
\hline P56 & 65,489 & ,000 & 19,929 & ,000 & 19,358 &, 000 \\
\hline P57 & 84,006 & ,000 & 65,889 & ,000 & 7,153 &, 007 \\
\hline P58 & 29,497 & ,000 & 22,931 & ,000 & 2,677 & 102 \\
\hline P59 & 56,062 & ,000 & 9,090 & ,003 & 21,914 &, 000 \\
\hline P60 & 5,536 & 019 & 300 &, 584 & 3,316 & ,069 \\
\hline P61 & 4,632 & ,031 & 3,430 & ,064 & ,488 & ,485 \\
\hline P62 & 17,928 & ,000 & 13,690 & ,000 & 45,898 & ,000 \\
\hline P63 & 1,518 & 218 & 1,144 & ,285 & , 145 & ,704 \\
\hline P64 & 6,585 & 010 & 2,730 & ,098 & 13,548 &, 000 \\
\hline
\end{tabular}

En la Tabla 9 se aprecia que, a pesar de existir diferencias significativas entre las tres etapas educativas en la mayoría de los ítems referidos a la participación familiar en el CE del centro, los bajos coeficientes de contingencia hallados demostraron que el valor típico de Cohen (1988) no fue alcanzado, ya que en todos los casos, dichos coeficientes de correlación fueron inferiores a 0,3 .

Tabla 9.

Coeficientes de contingencia de los items con significación estadística relativos a la participación familiar en CE del centro, en función de la etapa educativa

\begin{tabular}{|c|c|c|c|}
\hline & $\begin{array}{l}\text { Infantil- } \\
\text { Primaria }\end{array}$ & $\begin{array}{l}\text { Primaria- } \\
\text { Secundaria }\end{array}$ & $\begin{array}{c}\text { Infantil- } \\
\text { Secundaria }\end{array}$ \\
\hline & $\begin{array}{c}\text { Coeficiente } \\
\text { contingencia }\end{array}$ & $\begin{array}{c}\text { Coeficiente } \\
\text { contingencia }\end{array}$ & $\begin{array}{c}\text { Coeficiente } \\
\text { contingencia }\end{array}$ \\
\hline P51 & ,099 & 106 & -- \\
\hline P52 & 116, & 156, & ,025 \\
\hline P53 & ,094 & 133, & ,025 \\
\hline P54 & 051 & ,061 & -- \\
\hline P55 & 056 & 076, & 134 \\
\hline P56 & 086 & ,042 & 053 \\
\hline P57 & 097, & 076, & ,032 \\
\hline P58 & 059, & ,046 & -- \\
\hline P59 & 077, & ,028 & 054 \\
\hline P60 & ,024 & -- & -- \\
\hline P61 & ,022 & -- & -- \\
\hline P62 & ,044 & ,034 & ,078 \\
\hline P63 & -- & -- & -- \\
\hline P64 & ,027 & -- & ,043 \\
\hline
\end{tabular}

\section{Implicación de las familias en la AMPA y CE, en función de la titularidad del centro}

Respecto a la participación de las familias en la AMPA del centro, teniendo en cuenta la titularidad del mismo, en la Tabla 10 se aprecia que el $29,11 \%$, de los progenitores que han optado por instituciones públicas son los que más se implican en la AMPA, seguidos de los que llevan a sus hijos e hijas a centros concertados $(28,42 \%)$ y a privados $(24,71 \%)$, siendo estos últimos los que menos dificultades encuentran para participar $(11,11 \%)$.

Tabla 10.

Frecuencias y porcentajes de la participación familiar en la AMPA del centro, en función de su titularidad

\begin{tabular}{|c|c|c|c|c|c|c|c|c|c|c|c|c|}
\hline \multirow{3}{*}{ Ítem } & \multicolumn{6}{|c|}{ Frecuencia } & \multicolumn{6}{|c|}{ Porcentaje (\%) } \\
\hline & \multicolumn{2}{|c|}{ Público } & \multicolumn{2}{|c|}{ Concertado } & \multicolumn{2}{|c|}{ Privado } & \multicolumn{2}{|c|}{ Público } & \multicolumn{2}{|c|}{ Concertado } & \multicolumn{2}{|c|}{ Privado } \\
\hline & Sí & No & Sí & No & Sí & No & Sí & No & Sí & No & Sí & No \\
\hline P35 & 5338 & 3789 & 3000 & 1752 & 189 & 192 & 56,2 & 39,9 & 60,9 & 35,6 & 41,3 & 41,9 \\
\hline P36 & 4080 & 5013 & 1675 & 3029 & 153 & 233 & 43 & 52,8 & 34 & 61,5 & 33,4 & 50,9 \\
\hline P37 & 884 & 8126 & 327 & 4342 & 38 & 345 & 9,3 & 85,6 & 6,6 & 88,1 & 8,3 & 75,3 \\
\hline P38 & 2358 & 6539 & 1157 & 3480 & 130 & 250 & 24,8 & 68,9 & 23,5 & 70,6 & 28,4 & 54,6 \\
\hline P39 & 2982 & 5901 & 1251 & 3410 & 92 & 288 & 31,4 & 62,2 & 25,4 & 69,2 & 20,1 & 62,9 \\
\hline $\mathrm{P} 40$ & 1868 & 6890 & 1097 & 3536 & 92 & 281 & 19,7 & 72,6 & 22,3 & 71,8 & 20,1 & 61,4 \\
\hline P41 & 2698 & 6020 & 1736 & 2879 & 137 & 238 & 28,4 & 63,4 & 35,2 & 58,4 & 29,9 & 52 \\
\hline $\mathrm{P} 42$ & 1907 & 5242 & 959 & 2571 & 74 & 222 & 20,1 & 55,2 & 19,5 & 52,2 & 16,2 & 48,5 \\
\hline $\mathrm{P} 43$ & 2430 & 7060 & 1261 & 3667 & 105 & 353 & 25,6 & 74,4 & 25,6 & 74,4 & 22,9 & 77,1 \\
\hline
\end{tabular}




$\begin{array}{lcccccccccccc}\text { P44 } & 333 & 9157 & 95 & 4833 & 15 & 443 & 3,5 & 96,5 & 1,9 & 98,1 & 3,3 & 96,7 \\ \text { P45 } & 1899 & 7591 & 1109 & 3819 & 99 & 359 & 20 & 80 & 22,5 & 77,5 & 21,6 & 78,4 \\ \text { P46 } & 463 & 9027 & 246 & 4682 & 23 & 435 & 4,9 & 95,1 & 5 & 95 & 5 & 95 \\ \text { P47 } & 435 & 9055 & 149 & 4779 & 15 & 443 & 4,6 & 95,4 & 3 & 97 & 3,3 & 96,7 \\ \text { P48 } & 274 & 9216 & 107 & 4821 & 14 & 444 & 2,9 & 97,1 & 2,2 & 97,8 & 3,1 & 96,9 \\ \text { P49 } & 3825 & 5665 & 2058 & 2870 & 125 & 333 & 40,3 & 59,7 & 41,8 & 58,2 & 27,3 & 72,7 \\ \text { P50 } & 1762 & 7728 & 809 & 4119 & 65 & 393 & 18,6 & 81,4 & 16,4 & 83,6 & 14,2 & 85,8\end{array}$

Tras el cálculo de la prueba Chi Cuadrado, de los 48 contrastes realizados, se obtuvieron diferencias significativas en 22 de ellos (ver Tabla 11). Así, entre las familias que llevan a sus hijos e hijas a centros públicos y a concertados, la significación estadística se apreció en torno a los siguientes indicadores de participación: ser o haber sido socio/a de la AMPA (P35), conocimiento de los miembros de su Junta directiva (P36), formar parte de dicha Junta (P37), participación en las reuniones de la AMPA (P39), en actividades de formación para familias, socioculturales, de convivencia, etc. (P40), en actividades de acción social o de ayuda (P41) desconocimiento de lo que es la AMPA (P44), desinterés por participar en dicha asociación (P45), no sentirse capacitado para la participación (P47), no atreverse a participar (P48) y otro tipo de dificultades (P50).

Entre centros públicos y privados, las diferencias significativas se hallaron en los siguientes ítems: ser o haber sido socio/a de la AMPA (P35), conocimiento de los miembros de su Junta directiva (P36), estar dispuesto/a a ser parte de dicha Junta (P38), participación en las reuniones de la AMPA (P39), en actividades de acción social o de ayuda (P41), dificultades de horario para la participación (P49) y otro tipo de dificultades (P50).

Finalmente, entre las familias que llevan a sus hijos e hijas a centros concertados y a privados, la significación estadística se halló en los siguientes aspectos: ser o haber sido socio/a de la AMPA (P35), formar parte de dicha Junta (P37), estar dispuesto/a a ser parte de la misma (P38) y dificultades de horario para la participación (P49).

Tabla 11.

Significación estadística de la participación familiar en la AMPA del centro, en función de su titularidad

\begin{tabular}{|c|c|c|c|c|c|c|}
\hline & \multicolumn{2}{|c|}{$\begin{array}{l}\text { Pública- } \\
\text { Concertada }\end{array}$} & \multicolumn{2}{|c|}{$\begin{array}{l}\text { Pública- } \\
\text { Privada }\end{array}$} & \multicolumn{2}{|c|}{$\begin{array}{c}\text { Concertada- } \\
\text { Privada }\end{array}$} \\
\hline & $X^{2}$ & Sig. & $X^{2}$ & Sig. & $X^{2}$ & Sig. \\
\hline P35 & 28,118 & ,000 & 11,848 & ,001 & 27,422 & ,000 \\
\hline P36 & 109,378 & ,000 & 4,102 & ,043 & 2,516 & 113 \\
\hline P37 & 30,044 & ,000 & ,005 & ,943 & 4,497 & ,034 \\
\hline P38 & 3,818 & ,051 & 11,030 & ,001 & 15,787 & ,000 \\
\hline P39 & 64,442 & ,000 & 14,396 & ,000 & 1,243 & ,265 \\
\hline P40 & 9,698 & ,002 & 2,362 & ,124 & 186 & 667 \\
\hline P41 & 60,465 & ,000 & 5,228 & ,022 & , 174 & 677 \\
\hline P42 & 291 & ,589 & ,408 & ,523 & 651 & ,420 \\
\hline P43 & ,001 & ,982 & 1,653 & 199 & 1,570 & 210 \\
\hline P44 & 28,155 & ,000 & ,071 & 790 & 3,802 & ,051 \\
\hline P45 & 12,215 & ,000 & ,701 & ,402 & 190 & ,663 \\
\hline P46 & ,089 & ,766 & ,019 & 890 & ,001 & ,978 \\
\hline P47 & 20,317 & ,000 & 1,733 & 188 & ,090 & 764 \\
\hline P48 & 6,463 & ,011 & ,045 & 833 & 1,496 & ,221 \\
\hline P49 & 2,846 & ,092 & 30,904 & ,000 & 36,396 & ,000 \\
\hline P50 & 10,238 & ,001 & 5,577 & ,018 & 1,525 & ,217 \\
\hline
\end{tabular}

A pesar de estas diferencias significativas, los respectivos coeficientes de contingencia indicaron que, en ningún caso, se alcanzó el valor típico $(r=0,3)$ establecido por Cohen (1988), por lo que se puede afirmar que la magnitud de las diferencias (tamaño del efecto) no es suficientemente alta (Tabla 12).

Tabla 12.

Coeficientes de contingencia de los ítems con significación estadística relativos a la participación familiar en la AMPA del centro, en función de su titularidad

\begin{tabular}{|c|c|c|c|}
\hline & $\begin{array}{l}\text { Pública- } \\
\text { Concertada }\end{array}$ & $\begin{array}{l}\text { Pública- } \\
\text { Privada }\end{array}$ & $\begin{array}{c}\text { Concertada- } \\
\text { Privada }\end{array}$ \\
\hline & $\begin{array}{c}\text { Coeficiente } \\
\text { contingencia }\end{array}$ & $\begin{array}{c}\text { Coeficiente } \\
\text { contingencia }\end{array}$ & $\begin{array}{c}\text { Coeficiente } \\
\text { contingencia }\end{array}$ \\
\hline P35 & 045 & 035, & 073, \\
\hline P36 & 089, & 021 & -- \\
\hline P37 & 047 & -- & 030 \\
\hline P38 & -- & 034 & 056, \\
\hline P39 & 069, & 039, & -- \\
\hline P40 & 027 & -- & -- \\
\hline P41 & ,067 & ,024 & -- \\
\hline P42 & -- & -- & -- \\
\hline P43 & -- & -- & -- \\
\hline P44 & 044 & -- & -- \\
\hline P45 & 029 & -- & -- \\
\hline P46 & -- & -- & -- \\
\hline P47 & 038 & -- & -- \\
\hline P48 & ,021 & -- & -- \\
\hline P49 & -- & 056 & 082, \\
\hline P50 & ,027 & 024 & -- \\
\hline
\end{tabular}

En cuanto a la participación familiar en el CE del centro, en función de la titularidad del mismo, en la Tabla 13 se aprecian porcentajes medios más altos de participación familiar en el CE en los padres y madres que han elegido centros públicos $(33,77 \%)$, seguidos de los concertados $(29,94 \%)$ y de los privados $(24,46 \%)$, donde paradójicamente las familias encuentran menos dificultades para participar en el CE (15,57\%).

En el contraste entre centros públicos y concertados, la Tabla 14 muestra diferencias significativas en 9 de los 14 ítems analizados, concretamente en lo que respecta a: participación en las elecciones a CE (P51), conocimiento de sus representantes (P52), conocimiento del resto de miembros del CE (P53), ser o haber formado parte del CE (P54), conocimiento de las funciones de los representantes de las familias en el CE (P56), información recibida sobre los candidatos/as en las elecciones a CE (P58), desinterés para participar en las mismas (P62), falta de seguridad para presentarse a dichas elecciones (P63) y otro tipo de dificultades (P64). 
Tabla 13.

Frecuencias y porcentajes de la participación familiar en el CE del centro, en función de la titularidad

\begin{tabular}{|c|c|c|c|c|c|c|c|c|c|c|c|c|}
\hline \multirow{3}{*}{ Ítem } & \multicolumn{6}{|c|}{ Frecuencia } & \multicolumn{6}{|c|}{ Porcentaje (\%) } \\
\hline & \multicolumn{2}{|c|}{ Público } & \multicolumn{2}{|c|}{ Concertado } & \multicolumn{2}{|c|}{ Privado } & \multicolumn{2}{|c|}{ Público } & \multicolumn{2}{|c|}{ Concertado } & \multicolumn{2}{|c|}{ Privado } \\
\hline & Sí & No & Sí & No & Sí & No & Sí & No & Sí & No & Sí & No \\
\hline P51 & 3408 & 5633 & 1342 & 3355 & 90 & 269 & 35,9 & 59,4 & 27,2 & 68,1 & 19,7 & 58,7 \\
\hline P52 & 3279 & 5736 & 1421 & 3278 & 116 & 248 & 34,6 & 60,4 & 28,8 & 66,5 & 25,3 & 54,1 \\
\hline P53 & 2259 & 6665 & 1005 & 3641 & 92 & 271 & 23,8 & 70,2 & 20,4 & 73,9 & 20,1 & 59,2 \\
\hline P54 & 572 & 8433 & 200 & 4473 & 27 & 338 & 6 & 88,9 & 4,1 & 90,8 & 5,9 & 73,8 \\
\hline P55 & 2223 & 6672 & 1097 & 3539 & 104 & 261 & 23,4 & 70,3 & 22,3 & 71,8 & 22,7 & 57 \\
\hline P56 & 4350 & 4600 & 2082 & 2565 & 162 & 199 & 45,8 & 48,5 & 42,2 & 52 & 35,4 & 43,4 \\
\hline P57 & 4949 & 3985 & 2500 & 2129 & 164 & 196 & 52,1 & 42 & 50,7 & 43,2 & 35,8 & 42,8 \\
\hline P58 & 4612 & 4058 & 2157 & 2322 & 141 & 211 & 48,6 & 42,8 & 43,8 & 47,1 & 30,8 & 46,1 \\
\hline P59 & 1073 & 8417 & 601 & 4327 & 66 & 392 & 11,3 & 88,7 & 12,2 & 87,8 & 14,4 & 85,6 \\
\hline P60 & 1795 & 7695 & 993 & 3935 & 82 & 376 & 18,9 & 81,1 & 20,2 & 79,8 & 17,9 & 82,1 \\
\hline P61 & 514 & 8976 & 289 & 4639 & 36 & 422 & 5,4 & 94,6 & 5,9 & 94,1 & 7,9 & 92,1 \\
\hline P62 & 2937 & 6553 & 1678 & 3250 & 122 & 336 & 30,9 & 69,1 & 34,1 & 65,9 & 26,6 & 73,4 \\
\hline P63 & 848 & 8642 & 360 & 4568 & 24 & 434 & 8,9 & 91,1 & 7,3 & 92,7 & 5,2 & 94,8 \\
\hline P64 & 3082 & 6408 & 1482 & 3446 & 98 & 360 & 32,5 & 67,5 & 30,1 & 69,9 & 21,4 & 78,6 \\
\hline
\end{tabular}

Respecto a la significación estadística entre familias de centros públicos y privados, ésta se halló en los siguientes ítems: participación en las elecciones a CE (P51), información sobre el calendario de las mismas (P57), información recibida sobre los candidatos/as en las elecciones a CE (P58), desconocimiento de lo que es este órgano colegiado (59), falta de promoción para la participación por parte del equipo directivo (P61), escasez de seguridad para presentarse a las elecciones del CE (P63) y otro tipo de dificultades (P64).

Finalmente, se apreciaron diferencias significativas entre padres y madres de instituciones concertadas y privadas en los siguientes aspectos: ser o haber formado parte del CE del centro (P54), estar dispuesto/a a ser miembro del mismo (P55), información sobre el calendario de las elecciones a CE (P57), información sobre los candidatos/as en las elecciones a CE (P58), desinterés para participar en las mismas (P62) y otro tipo de dificultades (P64).

Tabla 14.

Significación estadística de la participación familiar en el CE del centro, en función de su titularidad

\begin{tabular}{ccccccc}
\hline & \multicolumn{2}{c}{$\begin{array}{c}c \\
\text { Pública- } \\
\end{array}$} & \multicolumn{2}{c}{$\begin{array}{c}\text { Pública- } \\
\text { Privada }\end{array}$} & \multicolumn{2}{c}{$\begin{array}{c}\text { Concertada- } \\
\text { Privada }\end{array}$} \\
& $\mathbf{X}^{2}$ & Sig. & $\mathbf{X}^{2}$ & Sig. & $\mathbf{X}^{2}$ & Sig. \\
\hline P51 & 113,744 &, 000 & 23,556 &, 000 & 2,015 &, 156 \\
P52 & 51,565 &, 000 & 3,074 &, 080 &, 423 &, 515 \\
P53 & 22,678 &, 000 &, 000 &, 990 & 2,714 &, 099 \\
P54 & 24,804 &, 000 &, 640 &, 424 & 7,646 &, 006 \\
P55 & 2,907 &, 088 & 2,285 &, 131 & 4,327 &, 038 \\
P56 & 17,722 &, 000 & 1,931 &, 165 &, 001 &, 979 \\
P57 & 2,372 &, 124 & 13,538 &, 000 & 9,588 &, 002 \\
P58 & 29,996 &, 000 & 23,423 &, 000 & 8,588 &, 003 \\
P59 & 2,498 &, 114 & 4,152 &, 042 & 1,895 &, 169 \\
P60 & 3,174 &, 075 &, 292 &, 589 & 1,324 &, 250 \\
P61 & 1,239 &, 266 & 4,997 &, 025 & 2,944 &, 086 \\
P62 & 14,341 &, 000 & 3,813 &, 051 & 10,349 &, 001 \\
P63 & 11,234 &, 001 & 7,461 &, 006 & 2,699 &, 100 \\
P64 & 8,659 &, 003 & 24,659 &, 000 & 15,215 &, 000 \\
\hline
\end{tabular}

A pesar de existir diferencias significativas en prácticamente la mitad de los contrastes realizados, en lo que respecta a la participación familiar en el CE de los respectivos centros, en función de la titularidad de los mismos, como indica la Tabla 15, en ningún caso el coeficiente de contingencia alcanzó el valor típico de Cohen (1988).

Tabla 15.

Coeficientes de contingencia de los ítems con significación estadística relativos a la participación familiar en el CE del centro, en función de su titularidad

\begin{tabular}{|c|c|c|c|}
\hline & $\begin{array}{c}\text { Pública- } \\
\text { Concertada }\end{array}$ & $\begin{array}{l}\text { Pública- } \\
\text { Privada }\end{array}$ & $\begin{array}{c}\text { Concertada- } \\
\text { Privada }\end{array}$ \\
\hline & $\begin{array}{l}\text { Coeficiente } \\
\text { contingencia }\end{array}$ & $\begin{array}{c}\text { Coeficiente } \\
\text { contingencia }\end{array}$ & $\begin{array}{c}\text { Coeficiente } \\
\text { contingencia }\end{array}$ \\
\hline P51 & 091 & ,050 & -- \\
\hline P52 & 061 & -- & -- \\
\hline P53 & 041 & -- & -- \\
\hline P54 & ,043 & -- & 039, \\
\hline P55 & -- & -- & 029, \\
\hline P56 & ,036 & -- & -- \\
\hline P57 & -- & ,038 & 044 \\
\hline P58 & ,048 & 051 & 042, \\
\hline P59 & -- & 020 & -- \\
\hline P60 & -- & -- & -- \\
\hline P61 & -- & ,022 & -- \\
\hline P62 & 032 & -- & ,044 \\
\hline P63 & ,028 & 027, & -- \\
\hline P64 & ,024 & 050 & 053, \\
\hline
\end{tabular}

\section{Discusión y conclusiones}

Atendiendo al primer objetivo, entendemos que la participación normativa de las familias se continúa circunscribiendo a pertenecer como socios a la AMPA, siendo simbólica o muy escasa la disposición a ser miembro de la Junta Directiva o a implicarse más activamente asistiendo a las actividades que organiza 
dicha asociación, resultados que se sitúan en la línea de otros estudios (García Sanz, Gomariz, Hernández Prados y Parra, 2010; Instituto Nacional de Calidad y Educación, 2003). Garreta (2008) también advertía de la reducida participación en actividades y reuniones convocadas por la AMPA, especialmente, en contextos de elevada concentración de población de origen no español, en los que la AMPA habría de jugar un papel relevante como asociación intermediaria entre el universo escolar y el universo familiar (Paniagua, 2013). Coincidiendo con Bolívar (2006), entre las nuevas líneas de acción que las AMPA pueden articular, se encuentra la potenciación de programas comunitarios. Se trata de desarrollar acciones que permitan conectar escuela, familias y entorno, atendiendo a las posibilidades del contexto y a las peculiaridades de la diversidad de familias.

Respecto a los obstáculos que impiden a las familias implicarse de manera activa en la AMPA, destacan la conciliación y la ausencia de interés. De hecho, la conciliación de horarios y tareas, máxime cuando ambos progenitores trabajan fuera de casa, se convierte en el obstáculo principal alegado por las familias para su implicación en la vida del centro escolar (Martínez-González et al., 2012), siendo "un condicionante importante de la participación que resulta, en ocasiones, complejo de modificar" (Rodríguez-Ruiz, Martínez-González y Rodrigo, 2016, p. 91).

En cuanto a su implicación en el CE, la dificultad estrella es la percepción de escasa competencia para esa labor, que concentra a más del $90 \%$ de los participantes, seguida de la falta de interés que muestra un tercio de las familias, proporciones similares a las manejadas en el estudio de Parra et al. (2014). Esta falta de interés sigue presente $y$, aunque puede estar relacionada con variables de carácter histórico y cultural, también es posible que el traspaso de competencias, atribuidas a este órgano colegiado, a otros órganos unipersonales como el director del centro escolar (Frías, 2014), no estén contribuyendo a minimizar.

Considerando la etapa educativa, podemos concluir que en Educación Primaria es donde parecen concentrarse los mayores niveles de participación de las familias a nivel normativo, tanto en AMPA como a través del CE, lo que evidencia el reto de conseguir mantener la implicación familiar en la etapa de Educación Secundaria. En esta etapa, las dificultades manifestadas por las familias siguen concentrándose en la incompatibilidad de horarios, así como en el escaso interés que tienen por implicarse más a través de la AMPA. En la etapa de Educación Infantil, al mismo tiempo que diversos estudios sitúan la participación familiar global en niveles más elevados en esta etapa respecto a etapas educativas posteriores (Garreta, 2008; Gomariz et al., 2008; Peñalver, 2009; Rodríguez-Ruiz et al., 2016), cabe señalar que de acuerdo con estudios previos (Parra, Gomariz, Hernández-Prados y García-Sanz, 2017) parece coexistir cerca de un $40 \%$ de familias cuyos hijos cursan Educación Infantil, que presentan niveles de participación normativa o formal muy bajos, tanto en AMPA como en CE. Esta participación de carácter indirecto suele ser menos frecuente respecto a la participación en actividades de aula (Maestre, 2009), de carácter más directo y por la que suelen optar las familias, especialmente en la etapa de Educación Infantil en la que se potencia más dicha colaboración a través de actividades de aula. No obstante, consideramos preciso idear nuevas estrategias para atraer a los órganos colectivos e indirectos de participación a aquellas familias más jóvenes, cuyos hijos e hijas cursan la etapa de Educación Infantil.

A pesar de luces y sombras, coincidimos con Garreta (2016) en que las AMPA están desarrollando un gran quehacer en los centros educativos de las distintas etapas para contribuir a la democratización real y efectiva de la educación. Pero tienen ante sí nuevos retos, y para avanzar hacia nuevas respuestas a una realidad educativa y social en continuo cambio, se hace preciso mejorar y ampliar la diversidad de vías de información, comunicación y difusión de las actividades que promueve dicha asociación, incorporando las TIC (páginas web, redes sociales, aplicaciones educativas,...) como estrategia de comunicación, tanto interna (entre la AMPA y el resto de familias) como externa (con equipo directivo y resto de profesionales del centro), promoviendo una combinación de las vías de comunicación tradicionales y las emergentes relacionadas con las tecnologías (Bernad y Llevot, 2016; Cavero y Calvet, 2016).

En relación con la titularidad del centro, encontramos mayores niveles de participación, tanto en la AMPA como en el $\mathrm{CE}$, en familias cuyos hijos asisten a centros públicos, frente a concertados y privados. En el estudio pormenorizado sobre implicación de las familias españolas en el CE (Parra et al., 2014) la participación en las elecciones a este órgano eran ligeramente superiores en los centros públicos, en la mayoría de Comunidades Autónomas, con respecto a los concertados (12,5\% frente a $11,2 \%)$. Las familias de centros privados son, paradójicamente, las que participan menos en AMPA y CE, y afirman encontrar menos dificultades en su implicación a través de ambos órganos, aunque también indican que el equipo directivo no promueve la participación en las elecciones a CE.

Generar nuevas y más intensas formas de participación de las familias en los centros contribuye a la calidad de nuestro sistema educativo y no depende del establecimiento de normativas legales, sino más bien, de que cada centro educativo establezca los cauces y recursos a través de los cuales mejorar esta implicación de las familias en la vida escolar, de acuerdo a su contexto y a la caracterización y necesidades de la comunidad educativa que acoge (Copash, 2006). De aquí, la importancia que se ha de conceder a la labor facilitadora por parte del centro y de su profesorado (Rodríguez-Ruiz et al., 2016), especialmente los tutores, de espacios, momentos, canales que promuevan el establecimiento de redes de colaboración entre la AMPA, el resto de familias, el equipo directivo y el conjunto del profesorado.

\section{Referencias bibliográficas}

Bernad, O., y Llevot, N. (2016). El papel de las AMPA en los centros escolares: actuaciones y retos. Revista de la Asociación de Sociología de la Educación, 9(3), 359-371. doi: https://doi. org/10.7203/RASE.9.3.8984

Bolívar, A. (2006). Familia y escuela: dos mundos llamados a trabajar en común. Revista de Educación, 339, 119-146. doi: http:// www.revistaeducacion.mec.es/re339_07.htm

Calvo, M., Verdugo, M. Á., y Amor, A. M. (2016). La participación familiar es un requisito imprescindible para una escuela inclusiva. Revista Latinoamericana de Educación Inclusiva, 10(1), 99-113. www.rinace.net/rlei/

Cavero, O. B., y Calvet, N. L. (2016). El papel de las AMPA en los centros escolares: actuaciones y retos. RASE: Revista de la Asociación de Sociología de la Educación, 9(3), 359-371. doi: https:// doi.org/10.7203/RASE.9.3.8984

Cohen, J. (1988) (2⿳亠口冋. ed.). Statistical Power Analysis for the Behavioral Sciences. New York: Academic Press.

Consejo Escolar del Estado (2017). Informe 2017 sobre el estado del sistema educativo. Madrid: MEC.

Constitución Española (1978). BOE del 29 de Diciembre de 1978.

Copasch (2006). Analysis of the current status of the cooperation between parents and school with models of good cooperation and recommendations for the network's further activities. Belfast: Copasch Network Partners. 
De Vellis, R. F. (2003) (2a. ed.). Scale development: Theory and applications. Thousand Oaks CA: Sage.

Epstein, J. L. (2011). School, Family and Community Partnerships. Preparing Educators and Improving Schools. Philadelphia: WESTVIEW Press.

Feito, R. (2014). Treinta años de consejos escolares. La participación de los padres y de las madres en el control y gestión de los centros sostenidos con fondos públicos en España. Profesorado. Revista de Currículum y Formación de Profesorado, 18(2), 51-67. doi: http://www.ugr.es/local/recfpro/rev182ART3.pdf

Frías, A. S. (2014). Evolución del marco normativo español sobre la participación de las familias. Contexto histórico. En Consejo Escolar del Estado (Coord.), La participación de las familias en la educación escolar (pp. 57-80). Madrid: Ministerio de Educación, Cultura y Deporte.

García Sanz. M. P., Gomariz, M. A., Hernández Prados, M. A., y Parra, J. (2010). La comunicación entre la familia y el centro educativo desde la percepción de los padres y madres de los alumnos. Educatio Siglo XXI, 28(1), 157-190. Recuperado de https://digitum.um.es/jspui/bitstream/10201/53742/1/La\%20 comunicacio \%CC $\% 81 \mathrm{n} \% 20$ entre $\% 201 \mathrm{la} \% 20$ familia $\% 20 \mathrm{y} \% 20$ el\%20centro\%20educativo\%20desde\%20la\%20percepcio\%CC\%81n $\% 20$ de $\% 201$ os $\% 20$ padres $\% 20 y \% 20$ madres $\% 20$ de $\% 20$ los\%20alumnos.pdf

García-Sanz, M., Hernández-Prados, M., Parra, J., y Gomariz, M. A. (2016). Participación familiar en la etapa de educación primaria. Perfiles Educativos, 38(154), 97-117. Recuperado de http://www.scielo.org.mx/scielo.php?script=sci_arttext\&pi$\mathrm{d}=\mathrm{S} 0185-26982016000400006$

Garreta, J. (2008). La participación de los padres en la escuela pública. Las asociaciones de madres y padres del alumnado. Madrid: CEAPA.

Garreta, J. (2010). La participación de las familias en la escuela. En R. Feito (Coord.), Sociología de la educación secundaria (pp. 47-66). Barcelona: Graó.

Garreta, J. (2012). Famílies i escoles: la participació de les famílies als centres educatius. La Paeria: Ajuntament de Lleida.

Garreta, J. (2016). Las asociaciones de madres y padres en los centros escolares de Cataluña: puntos fuertes y débiles. Revista Electrónica Interuniversitaria de Formación del Profesorado, 19(1), 47-59. doi: http://dx.doi.org/10.6018/reifop.19.1.245641

Gomariz Vicente, M. A., Parra Martínez, J., García-Sanz, M. P., Hernández-Prados, M. A., y Pérez Cobacho, J. (2008). La comunicación entre la familia y el centro educativo. Murcia: Consejo Escolar de la Región de Murcia. Recuperado de http:// www.cerm.es/publicaciones/la-comunicacion-entre-el-centro-educativo-y-la-familia/

Hernández-Prados, M. Á., y López-Lorca, H. (2006). Análisis del enfoque actual de la cooperación padres y escuela. Aula Abierta, 87, 3-25.

Instituto Nacional de Calidad y Educación (INCE) (2003). Diagnóstico general del Sistema Educativo. Comisión 5: Escuela y familia. Madrid: MECD.

Ley General de Educación (LGE) (1970). BOE n.ํำ 189.

Ley de Instrucción Pública (Ley Moyano) (1857). BOE n. 1660.

Ley Orgánica de Calidad en la Educación (LOCE) (2002). BOE n. $\mathbf{0} 307$.

Ley Orgánica de Educación (LOE) (2006). BOE n.ํำ 106.

Ley Orgánica del Derecho a la Educación (LODE) (1985). BOE n. ${ }^{\circ} 159$.

Ley Orgánica para la Mejora de la Calidad Educativa (LOMCE) (2013). BOE n. ํㅜㄹ. 295.

Ley Orgánica por la que se regula el Estatuto de Centros Escolares (LOECE) (1980). BOE n.ํำ
Llevot, N., y Bernad, O. (2015). La participación de las familias en la escuela: factores clave. RASE: Revista de la Asociación de Sociología de la Educación, 8(1), 57-70. doi: https://ojs.uv.es/index. php/RASE/article/view/8761/8304

Luengo, J., y Molina, J. (2016). Prácticas neoliberales y Nueva Gestión Pública: la construcción de la performatividad en la política educativa española. Actas del XV Congreso Nacional de Educación Comparada: Ciudadanía Mundial y Educación para el Desarrollo. Una mirada internacional. Sevilla. Sociedad Española de Educación Comparada y Universidad Pablo de Olavide.

Maestre, A. (2009). Familia y Escuela. Los pilares de la educación. Innovación y Experiencias Educativas, 14, 1-11. doi: http:// dx.doi.org/10.6018/reifop.18.2.219491

Martín Bris, M., y Gairín, J. (2007). Familias en la educación: un tema por resolver. Bordón, 59(1),113-151.

Martínez-González, R. A., Rodríguez-Ruiz, B., y Gimeno, J. L. (2010). Áreas de cooperación entre los centros docentes y las familias: estudio de caso. Educatio Siglo XXI, 28(1), 127-156.

Martínez-González, R. A., Rodríguez-Ruiz, B., y Rodrigo, M. J. (2012). Fathers' and teachers' perception about their partnership. En D. Hiatt-Michael y H. Z. Ho (Eds.), Promising practices for involvement in their children's education (pp. 79-93). Charlotte, NC: Information Age Publishing.

Mesa, R. (2014). Guía para Madres y Padres que participan en Consejos Escolares. Andalucía: CODAPA.

Pañellas, M., y Alguacil, M. (2009). El compromiso de las familias en una escuela entendida como espacio de trabajo en red adaptado a la realidad local. International Journal of Developmental and Educational Psychology, 2(1), 117-128. doi: http:// www.redalyc.org/articulo.oa?id=349832321012

Paniagua, A. (2013). Tan fuerte como su eslabón más débil. El caso de las AMPA en la integración escolar y social de las familias inmigradas. Revista Complutense de Educación, 24(1),69-89. doi: http://dx.doi.org/10.5209/rev_RCED.2013.v24.n1.41192

Parra, J., García Sanz, M. P., Gomariz, M. A., y Hernández Prados, M. A. (2014). Implicación de las familias en los Consejos Escolares de los centros. En Consejo Escolar del Estado. La participación de las familias en la educación escolar (pp. 149-164). Madrid: Ministerio de Educación, Cultura y Deporte. Recuperado de https://www.mecd.gob.es/dam/ jcr:8c2e037a-8673-4911-8594-d7aa12214d87/estudioparticipacion-pdf.pdf

Parra, J., Gomariz, M. A., Hernández-Prados, M. A., y García-Sanz, M. P. (2017). La participación de las familias en educación infantil. RELIEVE, 23(1), art. 4. doi: http://doi. org/10.7203/relieve.23.1.9258

Peñalver, R. (2009). El Plan Educa3, apostando por el primer ciclo de Educación Infantil. CEE Participación Educativa, 12 (monográfico Una mirada a la Educación Infantil), 8-19.

Rivas, S., y Ugarte, C. (2014). Formación docente y cultura participativa del centro educativo: claves para favorecer la participación familia-escuela. Estudios sobre Educación, 27, 153-168. doi: https://doi.org/10.15581/004.27.153-168

Rodrigo, Ma․ J., Martínez-González R. A., y Rodríguez-Ruiz, B. (2018). La Relación Centro Escolar-Familia como Factor Protector de Conductas Transgresoras en la Adolescencia. Aula Abierta, 47(2), 149-158. doi: https://doi.org/10.17811/rifie.47.2.2018.149-158

Rodríguez-Ruiz, B., Martínez-González, R. A., Rodrigo, Ma. J. (2016). Dificultades de las Familias para Participar en los Centros Escolares. Revista Latinoamericana de Educación Inclusiva, 10(1), 79-98. doi: https://scielo.conicyt.cl/pdf/rlei/v10n1/ art05.pdf 
Santos, M. A. (1997). El crisol de la participación: investigación etnográfica sobre consejos escolares. En F. Salvador, J. A. Ortega y M. Lorenzo (Coords.), Organización y dirección de instituciones educativas: perspectivas actuales. Actas de las I Jornadas Andaluzas sobre Organización y Dirección de centros educativos (pp. 77-106). Granada: Grupo Editorial Universitario.
Torres, M. (2013). El capital social en las asociaciones de madres y padres: Formación, desarrollo e institucionalización. Tesis doctoral. Granada: Universidad de Granada. 